\title{
Introduction
}

\section{Assistive technology and persons with developmental disabilities}

\author{
Tamar Heller* \\ Institute on Disability and Human Decelopment, Unicersity of Illinois, 1640 W. Roosecelt Road, Chicago, IL, USA
}

The theme of this issue is 'Assistive Technology and Persons with Developmental Disabilities.' Encompassing all ages, it focuses on assistive technology as a means of helping children and adults learn and maintain skills in settings ranging from school to work and home.

The targeted group, persons with a developmental disability, includes persons who have a severe, chronic physical and/or mental disability that manifests before age 22 years and results in a substantial functional limitation in three or more of the following areas of major life activity: selfcare, receptive and expressive language, learning, mobility, self-direction, capacity for independent living, and economic self-sufficiency. The two largest groups include persons with mental retardation and/or cerebral palsy.

The first article reports on a national survey of assistive technology use and the barriers to its use among adults with mental retardation. Michael L. Wehmeyer notes that assistive technology has generally been underutilized by persons with mental retardation, partly because fewer devices have been developed for cognitive versus physical

*Tel: +1 312 4131537; Fax: +13124131326 impairments. Secondly, even when devices exist, persons with cognitive impairments may have greater difficulty using them and understanding instructions regarding their use. Also, staff and families often are insufficiently aware of assistive technology, and funding for assessment and procurement of devices is insufficient.

In another article focusing on cognitive disability, Mats Granlund, Anders Bond, Elisabeth Lindstrom, and Birgitta Wennberg describe a model for developing assistive technology that differentiates between cognitive impairment, cognitive disability and cognitive handicap. They describe a case study conducted through the MENTEK project in Sweden, in which assistive technology was used either to minimize the disability across contexts with the help of a cognitive aid or to minimize the handicapping consequences of the disability in a specific context. These authors emphasize the importance of assessing cognitive handicaps in task analyses that take into account both the context and the tasks necessary for reaching the desired outcome.

The next group of articles addresses the communication needs of children. With the passage of the Education for the Handicapped Act Amendments of 1986 and the Individuals with 
Disabilities Education Act of 1991 (IDEA) in the United States, and with the Individualized Family Service Plans mandated by these laws, more young children are being provided with assistive technology. Improvements in functional language are frequently identified by families as goals for young children with disabilities. Parette's survey of augmentative and alternative communication (AAC) assessment and prescriptive practices exhibited by states points out the importance of paying attention to family issues in AAC assessments for young children. The second article on augmentative communication for children describes FACTT (Facilitating Augmentative Communication Through Technology), a model school-based program for children with mental retardation. The authors (Rose Sevcik, Mary Ann Romski, Vicki Collier, Cherry Rayfield, Betty Nelson, Ann Walton-Bowe, Dottie Jordan, Maryann Howell and Joan Ross) demonstrate how integration of assistive technology into the classroom, implementation of partner and child communicative use, inservice training, and administrative support can result in improved student achievements, professional development and public awareness about disability.

As persons with developmental disabilities move into adulthood, they have many of the same concerns as other adults; namely obtaining jobs and a career and finding residential placement. Unfortunately, people with developmental disabilities are largely excluded from the workforce and rarely live in independent settings. The landmark legislation, the Americans with Disabilities Act of 1990 (ADA), prohibits discrimination against persons with a disability in the workplace and requires that employers make reasonable accommodations for persons with disabilities who are otherwise qualified for a given job. John Leslie discusses the technological and attitudinal barriers that still exist to employment of persons with a disability and job accommodations that can facilitate their employment. One reason for employer resistance to accommodating persons with a disability is the perceived costs of these accommodations. Through case studies, Leonard Anderson illustrates the types of job accommodations that can be made and the associated costs.
The next four articles address the needs and usage of assistive technology by adults with developmental disabilities living in various residential settings. They also examine the role of assistive technology in facilitating transitions out of nursing homes and in maintaining functioning so that older adults can 'age in place.' As a result of the Omnibus Budget Reconciliation Act of 1987 (OBRA-87), which mandated that nursing facilities transfer inappropriately placed nursing facility residents with developmental disabilities into more appropriate residences, more than 10000 of these residents have moved out of nursing homes. Laurel A. Mendelson, Tamar Heller, and Alan R. Factor report on a longitudinal study of the functional limitations and assistive technology needs and uses of this group. They found that the greater the prevalence of functional limitations, the less likely people were to move out of nursing homes. The types of equipment most needed by the residents were wheelchairs and seating systems. Focusing on older adults, Jessica Presperin Pedersen discusses a program of providing wheelchair seating for individuals living in skilled nursing facilities, while Maria Aparecida Ferreira deMello and William C. Mann focus on the use of mobility related devices by older adults living in community residences. The latter study found the walker to be the most frequently used and effective device for this population. Ben Willems and Dina Loebl present a case study of the use of an adapted TV/VCR control for an individual with severe developmental disability about to transition from an institution to a community residence. They emphasize the important role of the staff in assisting the resident with daily routines and with the ongoing use of the assistive device.

The last section includes technical reports on devices that have been produced by the Center for Assistive Technology at the University of Buffalo. These include a VCR tape guide (Pat Sperle and Dale Johnson), adapted camera (JyhFang Jehng and Dale Johnson), horseback riding trunk support (Minoo Bengali, Russ Videtti and Pat Sperle), cassette tape guide (Pat Sperle and Dale Johnson), labeling jig (JyhFang Jehng and Dale Johnson), portable paraffin wax stand 
(Pat Sperle and Dale Johnson), assessment walker (Tomoko Kondo, Maria de Mello, Brian Riordan and Dale Johnson), and a supine positioner mold (Pat Sperle and Russ Videtti). These devices are examples of devices that could benefit persons with developmental disabilities and persons with other disabilities.

The challenge for the field is to continue developing assistive technology interventions for persons with developmental disabilities that will enable them to participate fully in the life of their community. This entails not only adequate assessment of functional impairments, but also assessments of the environmental context and ways to support the use of assistive technology in the settings in which people live, work and play.

\section{About the Author}

Tamar Heller, $\mathrm{PhD}$ Associate Professor of $\mathrm{Hu}-$ man Development, is Director of the Aging Studies Program and the Rehabilitation Research and Training Center (RRTC) on Aging with Mental Retardation at the Institute on Disability and Human Development (IDHD), University of Illi- nois at Chicago. She is also Associate Professor in Community Health Sciences and Psychology. The Aging Studies Program she directs includes the Illinois Geriatric Education Center, several large scale federally funded projects that bridge the aging and developmental disabilities network, and research projects on various home-based support interventions. The RRTC on Aging with Mental Retardation is a national resource of research and training, which brings together leading researchers at major universities and advocacy organizations to study aging and disabilities and to promote progressive public policies.

Previously, Dr. Heller had started and directed the IDHD Family Studies and Services Program, which included an interdisciplinary diagnostic clinic, a family support program and several large scale studies on lifespan family support issues. Her research has focused on residential transitions, family caregiving, and the effect of community and family supports on persons with a disability and their families. She has served on the boards of the American Association on Mental Retardation and the European Course on Mental Retardation. 